Nigerian Journal of Technology (NIJOTECH)

Vol. 33 No. 4, October 2014, pp. 490 - 496

Copyright(C) Faculty of Engineering,

University of Nigeria, Nsukka, ISSN: 111 15-8443

www.nijotech.com

http://dx.doi.org/10.4314/njt.v33i4.9

\title{
OPTIMIZING CONVENTIONAL DESIGN METHODS FOR REINFORCED CONCRETE RAFT FOUNDATIONS
}

\author{
G. A. Mahmud11,* and O. S. Abejide ${ }^{2}$ \\ 1,2 Department of Civil EngineERING, AHMAdu Bello University, ZaRia, NIGERIA. \\ E-mail addresses:1 mahmudja@gmail.com,2abejideos@yahoo.com
}

\begin{abstract}
Without a proper design and construction of foundations, problems such as cracking, settlement of buildings may occur and even to the extent that a whole building may collapse within its design life. Therefore, a proper and adequate foundation system is required to maintain the safety of a building. This presentation is the modeling of the requirements of compression reinforcements in raft foundations. The model helps to confirm a valuable provision to supplement the conventional theoretical design. For validation, a reinforced concrete raft foundation is modeled which is designed according to the current European code. Results indicate that there is differential settlement within the raft foundation based on the settlement and stress patterns obtained from a coded finite element model. This is followed by the addition of compression reinforcement from $0.1 \%$ to $0.9 \%$ based on the cross sectional area of the raft slab until uniform settlement is obtained. The results obtained suggest that a suitable percentage of the concrete cross section area of raft slab foundations should be used as compression reinforcement in order to prevent differential settlements. The required nominal area of compression reinforcement is $0.9 \%$ of the cross section area of the concrete section.
\end{abstract}

Keywords: compression reinforcement, raft foundations, finite element, optimization, flexure.

\section{INTRODUCTION}

Reinforced concrete rafts are designed to transmit the loads of the building in order to distribute them over the whole area under the raft and thereby reduce the load per unit area on the ground [1]. Distributing the loads this way causes little, if any, appreciable settlement [1]. But more precise methods, such as finite element computations, should be used in the design of raft foundations where ground-structure interaction has a dominant effect [2]. Subgrade reaction models are often not appropriate [2]. The design of a raft foundation is prone to significant uncertainties. The effect of the spatial variation of soil properties which induces foundation stresses and/or displacements that cannot be predicted when assuming soil homogeneity [3], the variation of elastic modulus of soil, presence of rock media and design uncertainties may give rise to differential settlement within the raft foundation and subsequently its structural failure.
Reinforced concrete is a complicated material to be modeled within finite element packages[4]. A proper material model in the finite element model should inevitably be capable of representing both the elastic and plastic behaviour of concrete in compression and tension [4]. If the finite element method is to be a useful tool in the design of reinforced concrete flat plate structures, accurate modeling is a pre-requisite [5]. Accurate modeling involves understanding the important relationships between the physical world and the analytical simulation. The importance of accurately modeling boundary conditions should never be underestimated or neglected in the analysis of any structure, particularly reinforced concrete flat plates [5]. ABAQUS is a powerful and comprehensive tool which provides the user with a powerful modeling environment, extensive library of material models, comprehensive meshing environment, comprehensive contact modeling capabilities, advanced analysis which include linear, nonlinear and robust multiphysics capabilities, high performance computing, best-in-class 
visualization capabilities, and analysis using specialized techniques.

This work presents the FEA modeling of the requirements of compression reinforcements in raft foundations using ABAQUS. The model helps to confirm and provide a valuable supplement to the theoretical design. For validation, a reinforced concrete raft foundation is modeled which is conventionally designed according to Eurocode [6] provisions. The results indicate that there is differential settlement within the raft foundation based on the settlement and stress patterns obtained from the finite element model (FEM). This is followed by the addition of compression reinforcement from $0.1 \%$ to $0.9 \%$ based on the cross sectional area of the raft slab until uniform settlement is obtained.

\section{DESIGN OF SIMPLE RAFT FOUNDATIONS}

A reinforced concrete raft foundation is conventionally designed according to Eurocode [6]. The raft consists of eight column loads with four corner and four internal loads of an office building. All the corner columns carry a load of $458.33 \mathrm{KN}$ each and internal columns carry $666.66 \mathrm{KN}$ each. Each column has an area of $0.5 \mathrm{~m}$ by $0.5 \mathrm{~m}$. The assumed bearing capacity of the soil is $100 \mathrm{KN} / \mathrm{m}^{2}$ and is assumed to be distributed linearly. Soil density is assumed to be firm with two or more types of soil forming the sub-soil. The area of the foundation is calculated as $75 \mathrm{~m}^{2}$ and a dimension of $5 \mathrm{~m}$ by $15 \mathrm{~m}$ is chosen for the foundation. The number and area of reinforcements are derived using the most critical values of the shear forces and bending moments.

Compression reinforcement is then added to the design at various percentages ranging from $0.1 \%$ to $0.9 \%$ of the cross sectional area of the raft slab.

\section{FINITE ELEMENT ANALYSIS}

The size and dimension of the soil layer and raft foundation model adopted for the finite element analysis can be seen in the diagram shown in Figure 2.

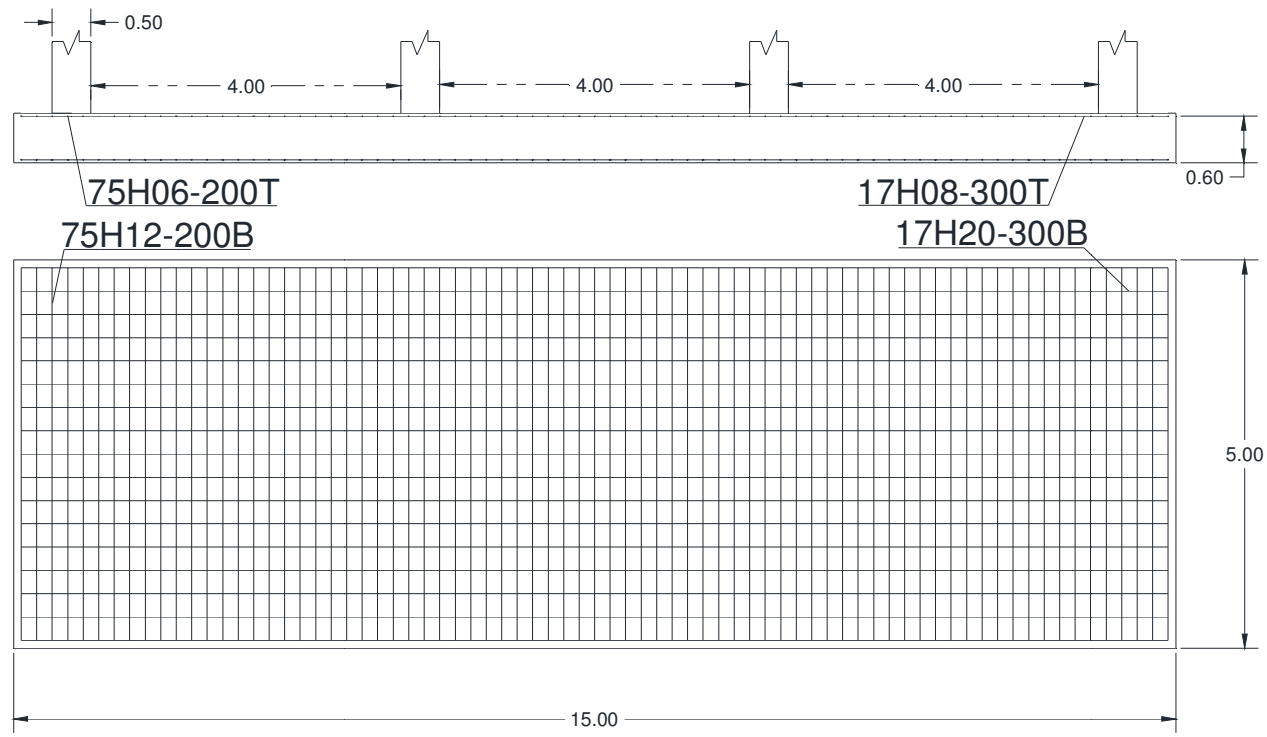

BOTTOM PLAN

Figure 1: Reinforcement detailing of the designed raft foundation

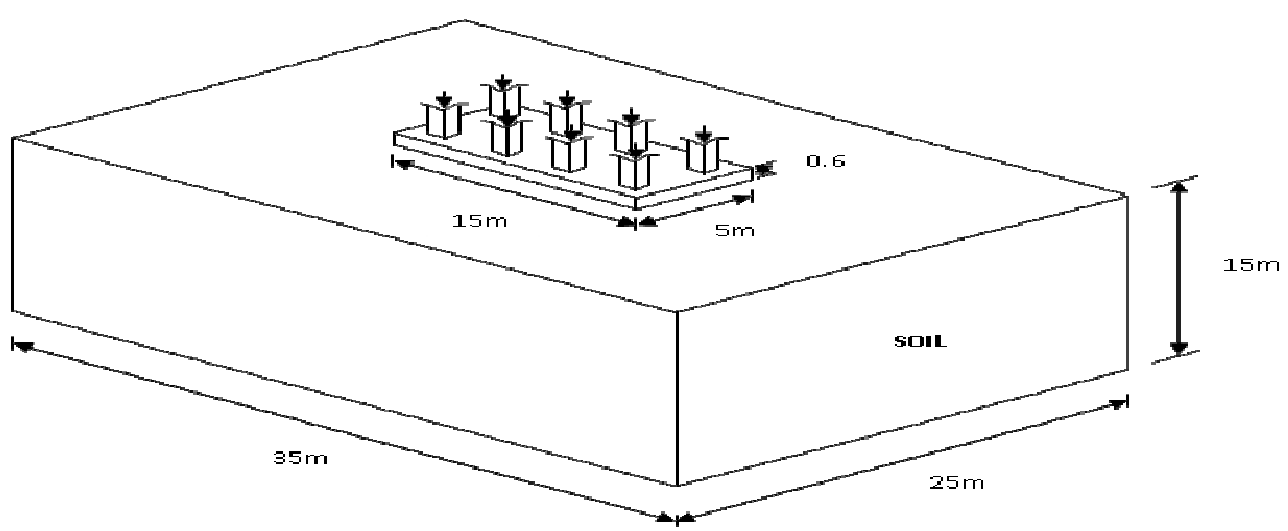

Figure 2: Raft foundation and soil layer configuration adopted for the finite element analysis. 
The 3D deformable solid parts involved in the analysis consist of the soil layer, concrete slab and steel reinforcements. The dimensions of the steel reinforcements used are obtained from the foundation design as seen in Figure 1 while the dimension of the soil layer and the slab can be seen in Figure 2. Figures 3 to 9 show the stepwise modeling of the foundation raft and components in ABAQUS.

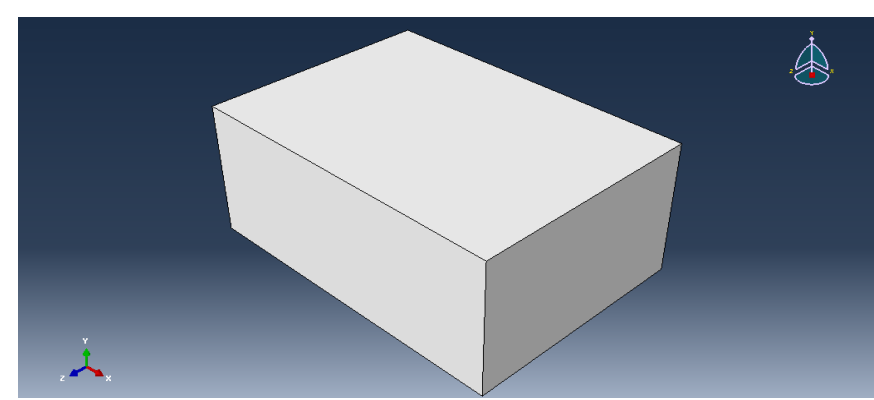

Figure 3: Soil layer part in ABAQUS

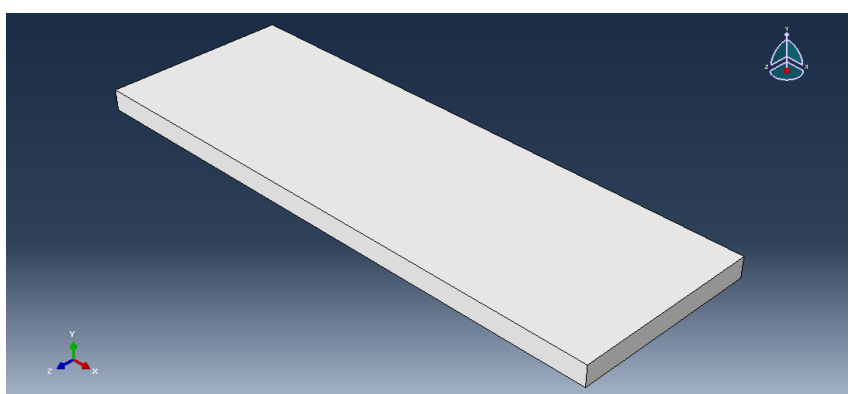

Figure 4: Concrete slab part in ABAQUS

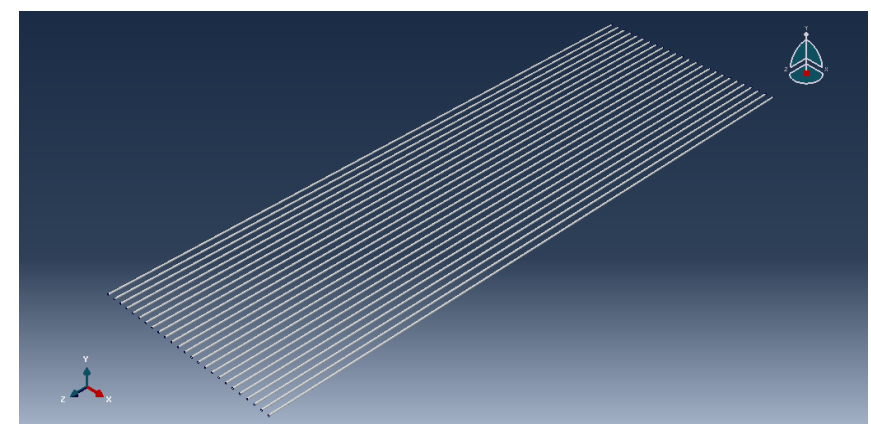

Figure 5: Tensile reinforcement running along the length

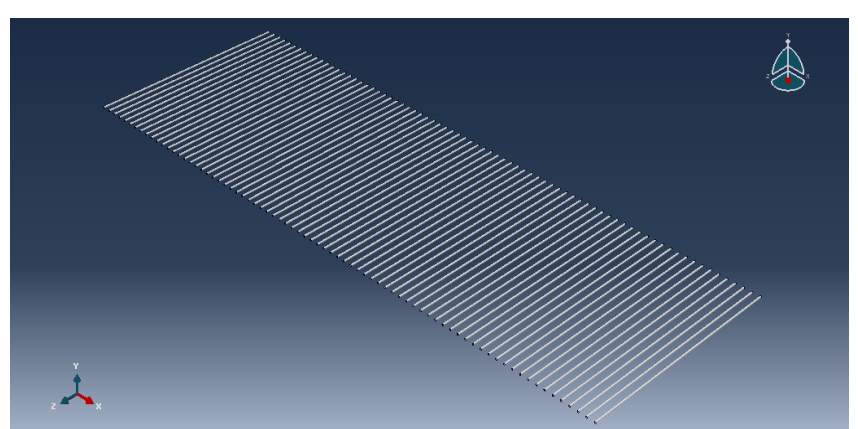

Figure 6: Tensile reinforcement running along the width
Elastic soil, concrete and steel are used to define the properties of the parts in the model. Soil, concrete and steel sections are then created using these properties and the sections assigned to the individual parts accordingly. An elastic material is used for the soil with an isotropic hardening rule. Elastic foundations allow one to model the stiffness effects of a distributed support without actually modeling the details of the support $[7,8]$.

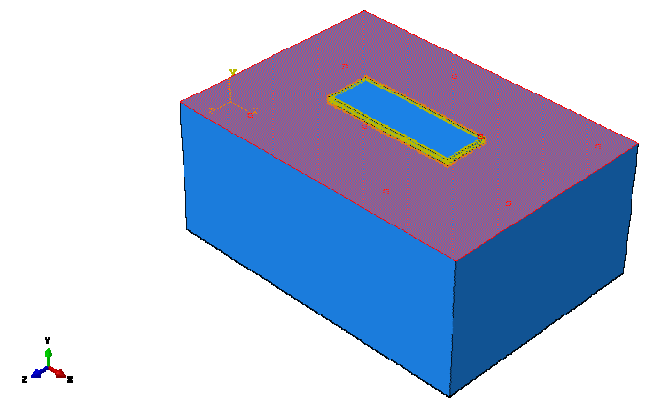

Figure 7: Interaction between concrete slab and elastic soil surface

The soil material is assumed to have a density of $1900 \mathrm{~kg} / \mathrm{m}^{3}$ and is assigned a Poisson's ratio of 0.3 . Foundation stiffness per area of $100 \times 10^{3} \mathrm{~N} / \mathrm{m}^{2}$ is applied to the top surface of the soil layer. A compressive strength of $45 \mathrm{MPa}$ is assigned to the concrete part. A plastic strain of 0.0035 and a density of $2400 \mathrm{~kg} / \mathrm{m}^{3}$ are also assumed for the concrete. The Young's modulus and Poisson's ratio are taken to be 36GPa and 0.2 respectively. An elastic, perfectly plastic material is used for the reinforcing bars. The reinforcing bars are 3D solid elements embedded in the concrete. They exhibit an elastic-plastic behavior and transfer of loads to the concrete through the reinforcements is achieved by introducing tension stiffening to the concrete model. The embedded element option is used to model the interaction/bond between the concrete and reinforcing bars. The reinforcing bars are the embedded elements while the concrete slab is the host element. A solid homogeneous steel section is assigned to the reinforcing bars with isotropic hardening. The steel is assigned a tensile strength and strain of 500MPa and 0.003 respectively. The density of steel is taken as $7850 \mathrm{~kg} / \mathrm{m}^{3}$. A Young's modulus and Poisson's ratio of 200GPa and 0.3 are assigned to the reinforcements respectively.

Linear hexahedral elements of type C3D8R prescribed in ABAQUS are used in defining the mesh for the entire assembly. This fine mesh will help in improving the accuracy of the results obtained after the analysis. 


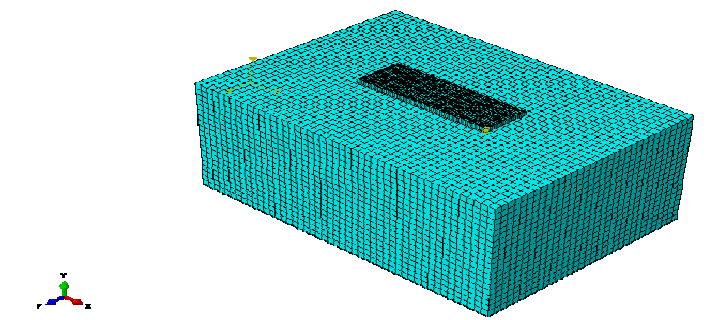

Figure 8: Discretization of structure into elements and nodes.

Concentrated loads and boundary conditions are applied to the assembly on the surfaces of the parts. The loads are applied on the surface of the nodes of the concrete slab. Four edge loads and four internal loads are applied with magnitudes of $458.33 \times 10^{3} \mathrm{~N}$ and $666.66 \times 10^{3} \mathrm{~N}$ respectively. The loads are applied along the $y$-axis and are given a negative value for downward action. An encastre boundary condition (U1 = U2 = U3 $=\mathrm{UR} 1=\mathrm{UR} 2=\mathrm{UR} 3=0$ ) is applied to the sides and bottom of the soil block which restricted it from moving or rotating in all directions. The top surface of the soil layer is not restricted and is allowed to deform in all directions. The edges of the slab are assigned a boundary condition in the form of YASYMM (U1 = U3 $=\mathrm{UR} 2=0$ ) which only allows movement along the $\mathrm{y}$ axis and rotation along both $\mathrm{x}$-axis and z-axis. The aim of this is to allow the raft foundation to deform in the direction of the loads.
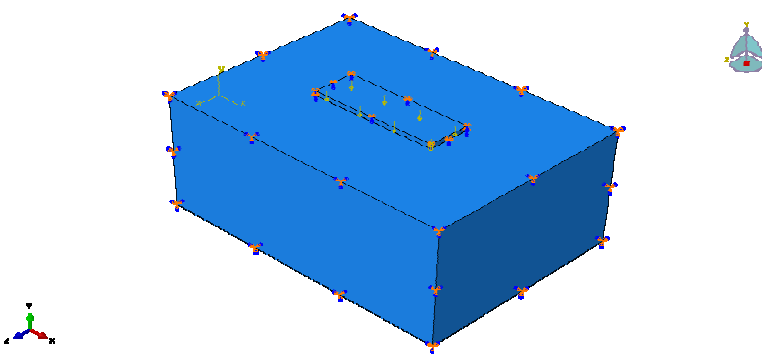

Figure 9: Applied loads and boundary conditions

There are two steps involved in this analysis; the initial and the created "slab load step". Interactions are created in the initial step while loads and boundary conditions are created and applied in the slab load step. The slab load step has a maximum number of 100 increments. The initial increment size is 1 , the minimum 1E-005 and the maximum 1.

A set of field output and history output requests are created in the slab load step. A full analysis job is created, submitted and run with results obtained. The analysis is repeated for models with additional amount of compression reinforcement; the additional amount ranging from $0.1 \%$ to $0.9 \%$ of the cross sectional area of the raft slab.

\section{RESULTS AND DISCUSSION}

The finite element analysis carried out for a normally designed draft foundation model according to the provisions of the code yielded results indicating that the tensile reinforcement provided is insufficient to provide adequate resistance against deformation and differential settlement. The addition of compression reinforcement increases the resistance until uniform settlement is obtained at a value $0.9 \%$ of the concrete cross section area of the raft slab.

\subsection{Stress patterns in the raft foundation}

The Von Mises stress pattern obtained after the analysis for the raft foundation models can be seen in the deformed diagram of the models shown in Figures 10 to 17 . The Von Mises stress refers to the theory called Maxwell-Huber-Hencky-Von Mises criterion for ductile failure [7]. The analysis shows that there are no Von Mises stresses within all the raft foundation models. The contour blue indicates zero Von Mises stresses and hence, it is an indication that the foundation is stable after the deformation caused by the applied loads.

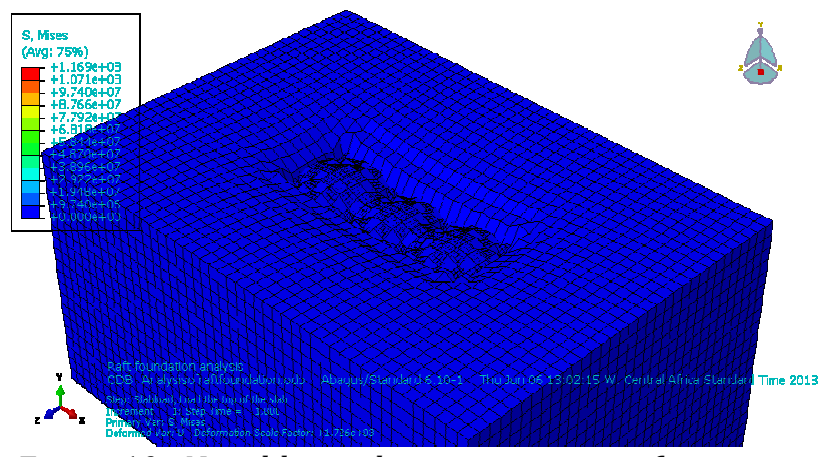

Figure 10: No additional compression reinforcement

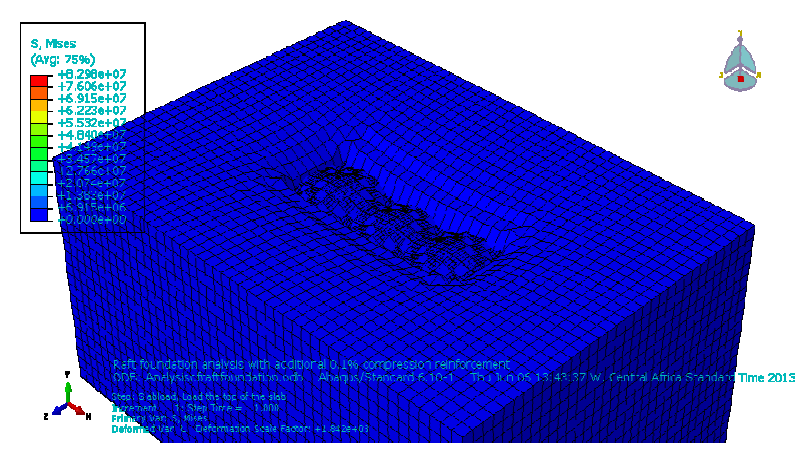

Figure 11: 0.1\% additional compression reinforcement 


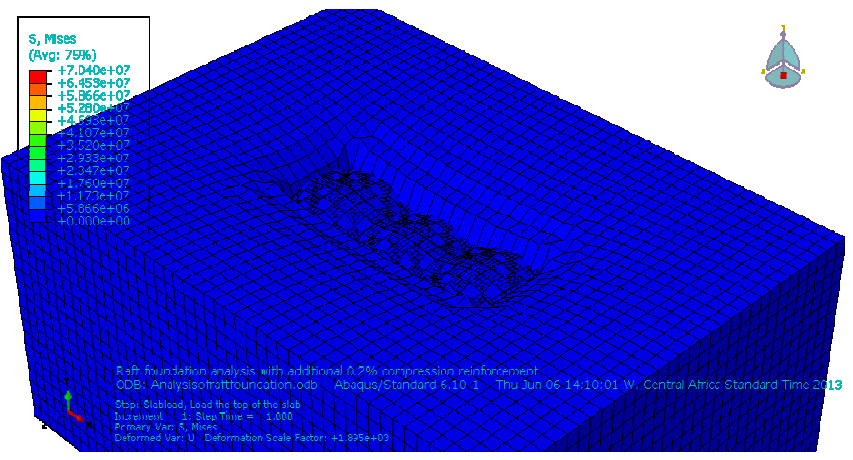

Figure 12: 0.2\% additional compression reinforcement

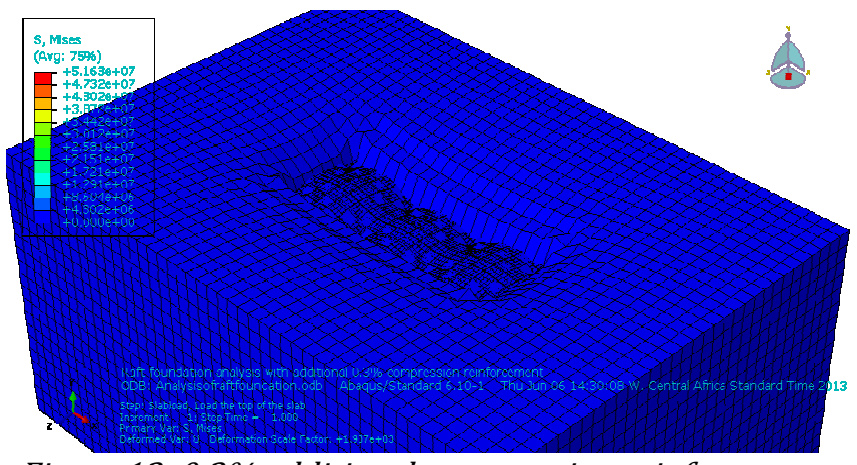

Figure 13: 0.3\% additional compression reinforcement
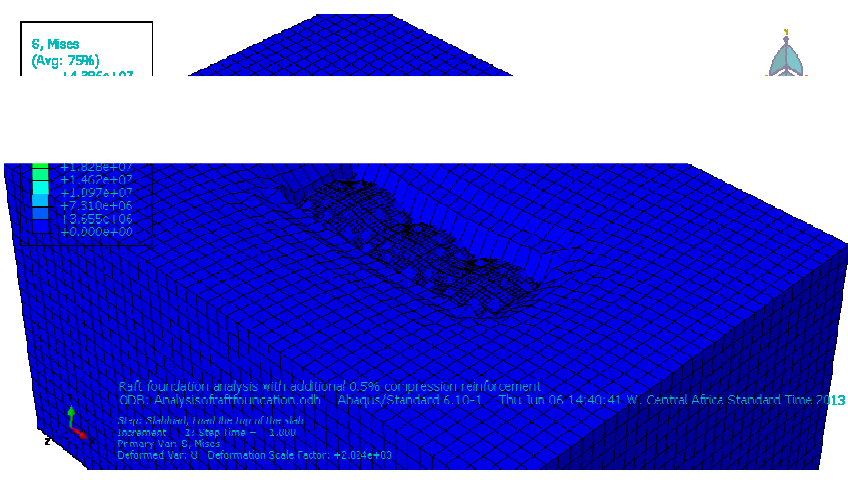

Figure 14: 0.5\% additional compression reinforcement

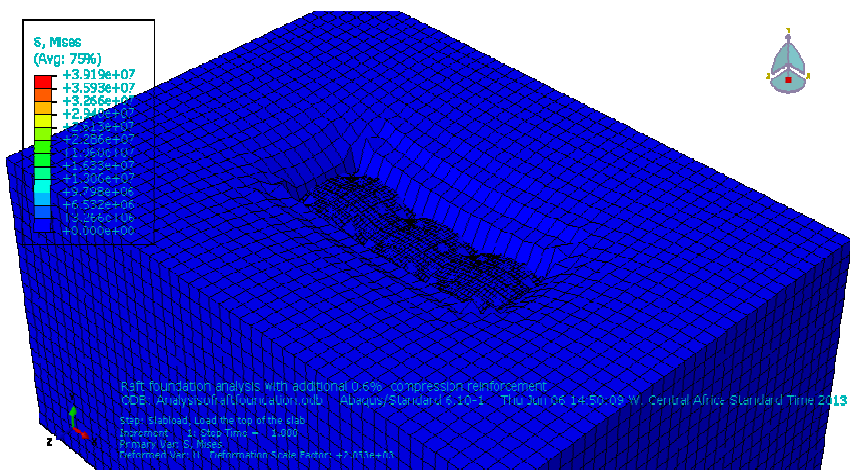

Figure 15: 0.6\% additional compression reinforcement

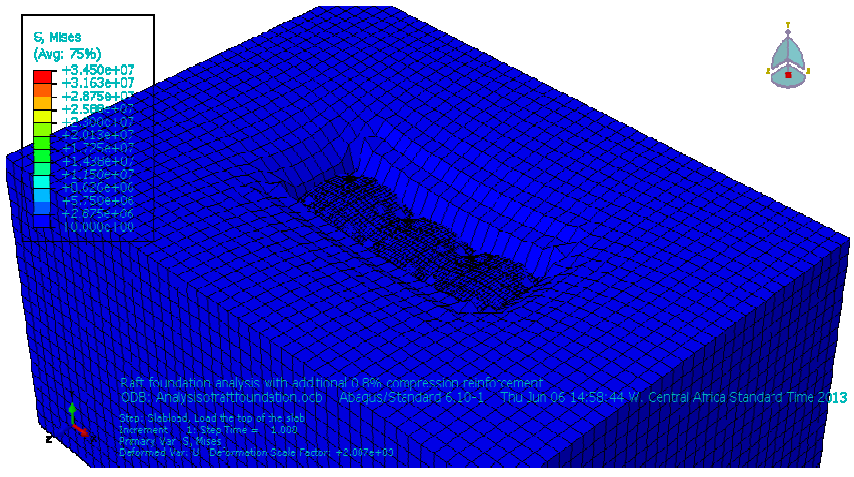

Figure 16: 0.8\% additional compression reinforcement

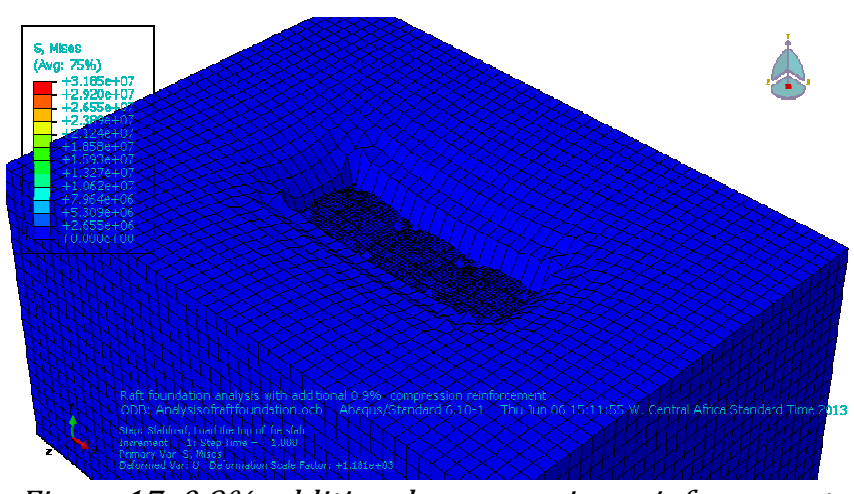

Figure 17: 0.9\% additional compression reinforcement

\subsection{Settlement of the raft foundation}

The immediate settlement of the raft foundation models takes place in the direction in which the load is applied. The spatial displacement of the models can be seen in Figures 18 to 25 . It can also be seen that the maximum immediate settlement in the normally designed raft foundation model according to the provisions of the design code [6] occurred at the points where the loads are applied while the minimum immediate settlement occurred at the center where there is an upward heave. The result indicates that there is differential settlement in the raft foundation after the deformation. After the application of compression reinforcement, a uniform settlement is obtained at $0.9 \%$ as shown in Figure 25.

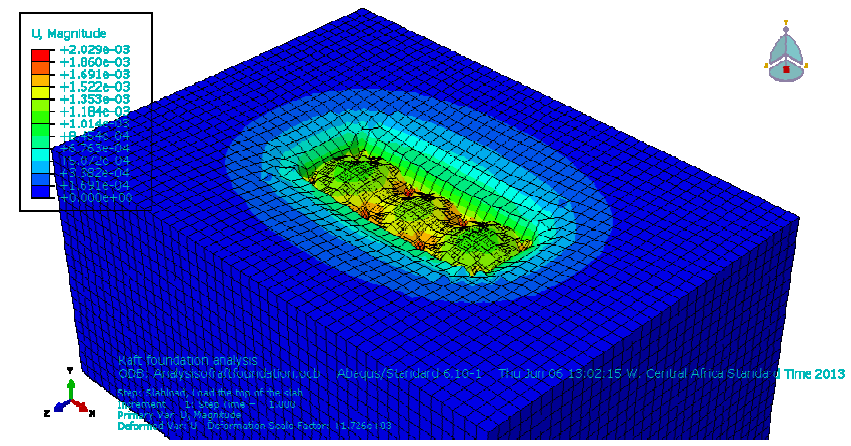

Figure 18: No additional compression reinforcement 


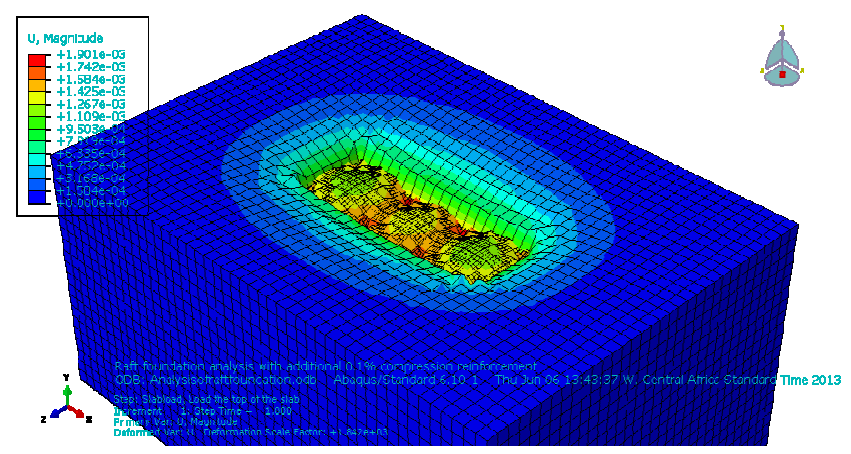

Figure 19: 0.1\% additional compression reinforcement

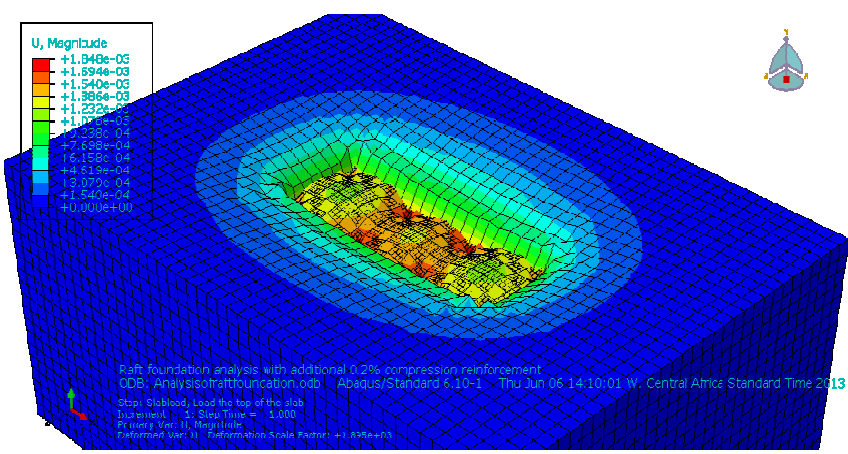

Figure 20:0.2\% additional compression reinforcement

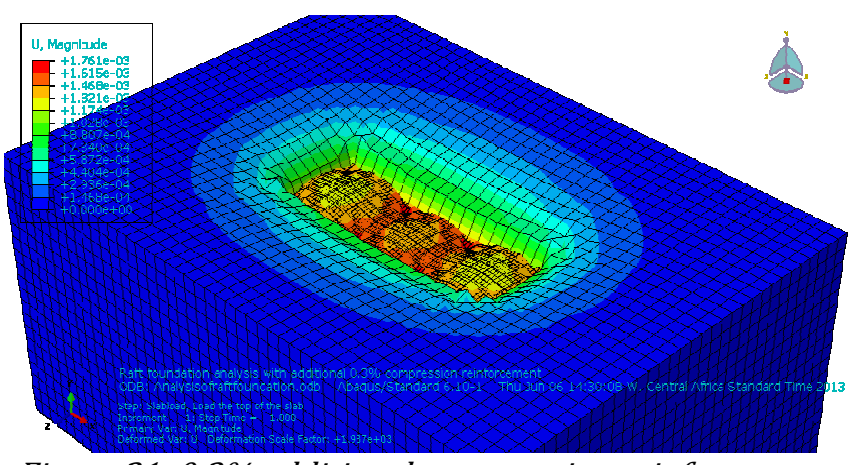

Figure 21: 0.3\% additional compression reinforcement

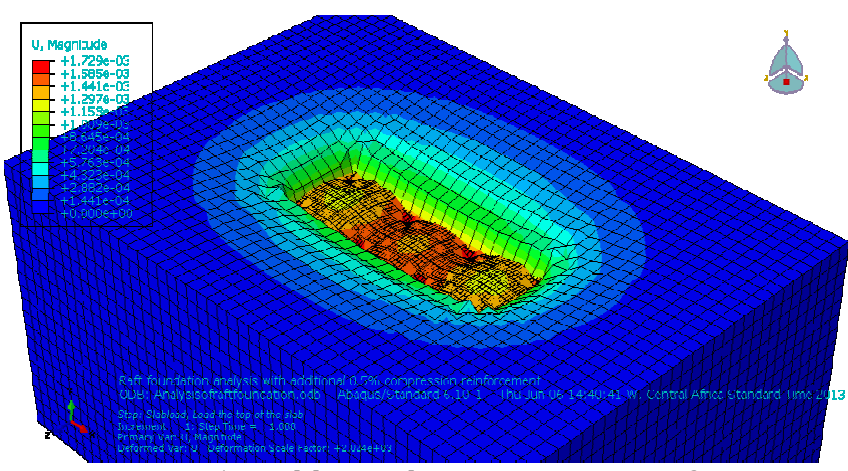

Figure 22: $0.5 \%$ additional compression reinforcement

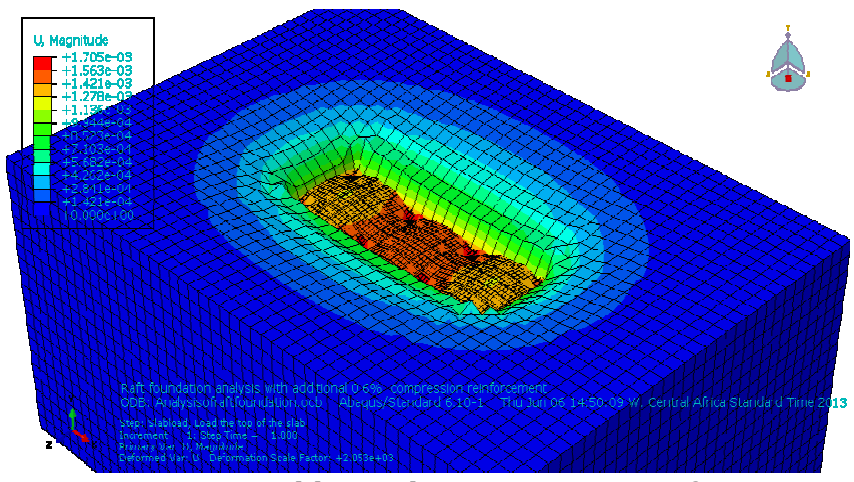

Figure 23: 0.6\% additional compression reinforcement

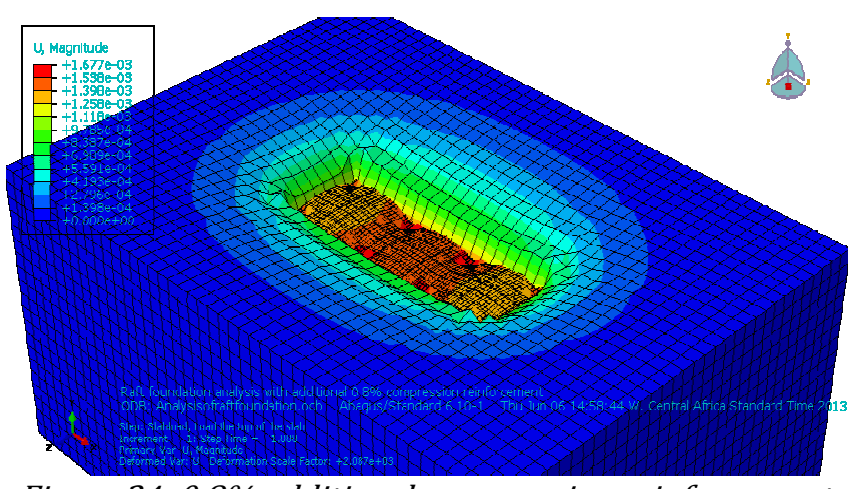

Figure 24: 0.8\% additional compression reinforcement

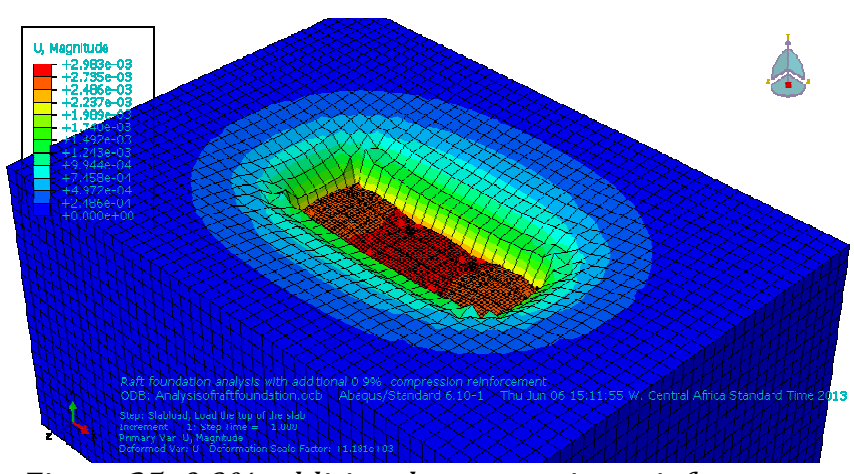

Figure 25: 0.9\% additional compression reinforcement

\section{CONCLUSION}

On the basis of the study carried out, the following conclusions may be drawn:

I. The variation of the amount of reinforcement in compression and tension in a raft foundation plays a significant role and affects the moments and deformations of the foundation.

II. Compression reinforcement is effective in providing resistance against differential settlement in a reinforced concrete raft foundation.

III. Settlement estimates of a foundation is the best guess of the footing deformation after a load has been applied as proved from the nodal representations of elements in the finite element analysis display. 
IV. The overall settlement of the raft foundation was reduced by about $80 \%$ due to the increase in the stiffness of the foundation, indicating that settlements can be reduced by up to $80 \%$ when it occurs.

V. The finite element analysis is a very precise method for the design and analysis of raft foundations.

It is therefore suggested that a suitable percentage of the concrete cross section area of raft slab foundations should be used as compression reinforcement in order to increase the foundation stiffness and prevent differential settlements. The amount of compression reinforcement is derived from the more precise method of finite element analysis by comparing results from the conventional design method in terms of the code's provisions for differential settlement within the raft foundations. This amount is obtained as $0.9 \%$ of the concrete cross section for the current design code [6] and may be generally applied for the design of reinforced concrete raft foundations.

\section{REFERENCES}

[1] Stephen Emmitt and Christopher Gorse A.Barry's Introduction to Construction of Buildings, $2^{\text {nd }}$ Edition, John Wiley and Sons. pp .61 - 64, 2010.
[2] Eurocode 7: EN 1997-1Geotechnical Design - Part 1: General Rules. European Standard, CEN, Brussels, 2004.

[3] Niandou, Halidou/Breysse, Denys"Reliability Analysis of a Piled Raft Accounting for Soil Horizontal Variability",Computers and Geotechnics, 34 (2). pp 71-80,2006.

[4] SinaeiHamid, Mahdi Shariati, Amir HoseinAbna, Mohammed Aghael and Ali Shariati, "Evaluation of Reinforced Concrete Beam BehaviorUsing Finite Element Analysis by ABAQUS",Academic Journal, Scientific Research and Essays Vol. 7(21), pp. 20022009, 7 June, 2012

[5] Deaton James B."A Finite Element Approach to Reinforced Concrete Slab Design",School of Civil and Environmental Engineering Thesis, Georgia Institute of Technology, Virginia, pp. 11-25,2005.

[6] Eurocode 2: EN 1992-1-1Design of Concrete Structures - Part 1-1: General Rules and Rules for Buildings, CEN, Brussels,2008.

[7] Hand F. R., Pecknold D. A. and Schnobrich W. C."A Layered Finite Element Nonlinear Analysis of Reinforced Concrete Plates and Shells"Civil Engineering Studies, SRS No. 389, University of Illinois, Urbana, Illinois, 1972.

[8] SimuliaDassaultSystemes"ABAQUS Unified FEA3DSDassaultSystemes",http://www.3ds.com/. Last accessed 4/10/2012. 